\title{
The effect of a diet supplemented with flaxseed oil on the lipid content and fatty acid profile of rainbow trout (Oncorhynchus mykiss) muscle tissue
}

\author{
Jason P. Nguyen \\ West Virginia University
}

Follow this and additional works at: https://researchrepository.wvu.edu/etd

\section{Recommended Citation}

Nguyen, Jason P., "The effect of a diet supplemented with flaxseed oil on the lipid content and fatty acid profile of rainbow trout (Oncorhynchus mykiss) muscle tissue" (2006). Graduate Theses, Dissertations, and Problem Reports. 2468.

https://researchrepository.wvu.edu/etd/2468

This Thesis is protected by copyright and/or related rights. It has been brought to you by the The Research Repository @WVU with permission from the rights-holder(s). You are free to use this Thesis in any way that is permitted by the copyright and related rights legislation that applies to your use. For other uses you must obtain permission from the rights-holder(s) directly, unless additional rights are indicated by a Creative Commons license in the record and/ or on the work itself. This Thesis has been accepted for inclusion in WVU Graduate Theses, Dissertations, and Problem Reports collection by an authorized administrator of The Research Repository @ WVU. For more information, please contact researchrepository@mail.wvu.edu. 


\title{
THE EFFECT OF A DIET SUPPLEMENTED WITH FLAXSEED OIL ON THE LIPID CONTENT AND FATTY ACID PROFILE OF RAINBOW TROUT (ONCORHYNCHUS MYKISS) MUSCLE TISSUE
}

\author{
Jason P. Nguyen \\ Thesis submitted to the College of Agriculture, Forestry, and Consumer \\ Sciences at West Virginia University \\ In partial fulfillment of the requirements \\ For the degree of
}

Master of Science

In

Family and Consumer Sciences

Jacek Jaczynski, Ph.D., Chair

Cindy Fitch, Ph.D.

Kenneth Semmens, Ph.D.

Division of Animal and Veterinary Sciences

Morgantown, West Virginia

2006

Keywords: flaxseed oil, omega-3 fatty acids, fat, rainbow trout, fish fillets 


\title{
ABSTRACT \\ The Effect of a Diet Supplemented with Flaxseed Oil on the Lipid Content and Fatty Acid Profile of Rainbow Trout (Oncorhynchus mykiss) Muscle Tissue
}

\begin{abstract}
Jason Nguyen
This experiment examined the effect of nine diets supplemented with varied combinations of flaxseed oil and vitamin $\mathrm{E}$ on the total lipid content and fatty acid profile of rainbow trout over four months. Mean values were tested for significant differences between groups using one-way analyses of variance.

The most flaxseed oil supplementation, $23.5 \%$, resulted in the highest concentration of total omega-3 fat in fillets $(\mathrm{P}<0.05)$. This was due to the increased $(\mathrm{P}<0.05)$ concentration of alpha-linolenic acid (ALA). The $23.5 \%$ flaxseed oil trout had the lowest $(\mathrm{P}<0.05)$ proportion of saturated fatty acids and the highest amount of total unsaturated fatty acid. Unexpectedly, eicosapentaenoic acid (EPA) and docosahexaenoic acid (DHA) contents significantly decreased as the experiment progressed. No significant differences were seen among total fat contents. The results indicate that feeding a diet supplemented with flaxseed oil and vitamin E produces omega-3 enhanced trout with higher ALA but lower EPA and DHA.
\end{abstract}




\section{Acknowledgements}

This study was performed as part of the Aquaculture Food and Marketing Development Project (AFMDP) at West Virginia University and funded by grant No. 99-34386-8465 from the USDA Cooperative State Research, Education, and Extension Service. I wish to offer special thanks to Dr. Jacek Jaczynski for his guidance, organization, and knowledge. I also would like to thank my committee members, Dr. Kenneth Semmens and Dr. Cindy Fitch, for their work and help on this project. Sincere gratitude goes to Sarah K. Beamer, Chestina Merriner, Dr. P. Brett Kenney, Dr. Yi-Chen Chen, Rodney Kiser, and Jennifer Black for their assistance with this project. 


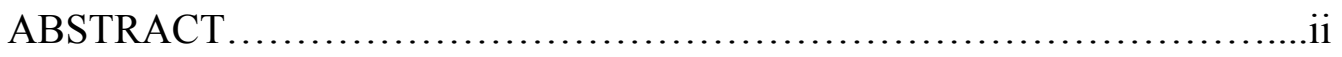

ACKNOWLEDGEMENTS.............................................ii

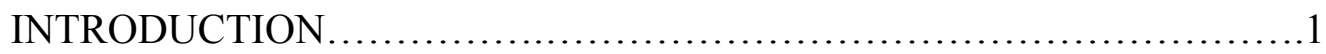

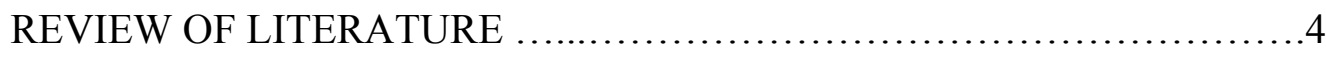

I. The role of omega-3 fatty acids in human health................4

II. The ratio between omega-3 and omega- 6 fatty acids...........7 and the Western diet

III. Efforts to increase EPA and DHA in fish.....................9

STATEMENT OF THE PROBLEM........................................ 12

MATERIALS AND METHODS............................................

Experimental Design...........................................13

Rainbow trout and diets.......................................... 14

Table 2: Grower-standard pellet diet...............................15

Table 3: Raceway design and experimental diets....................16

Sample selection.................................................

Sample preparation and moisture assay ...........................17

Lipid measurements.......................................... 18

Statistical Analyses................................................. 19

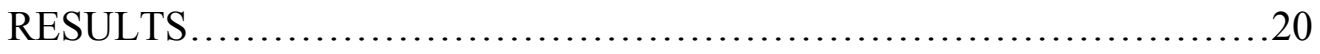

Table 5: Total fat (\%) of trout fillets as affected by supplementing feed with flaxseed oil .............................21

Table 6: Fatty acid profile in trout fillets as affected by feed supplementation with flaxseed oil 


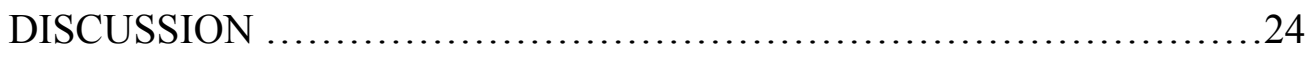

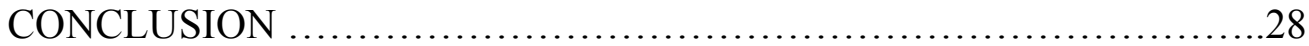

REFERENCES ............................................... 30 


\section{Introduction}

Awareness and interest in the omega-3 fat content of foods is now stronger than ever. Advertisements and food labels market products containing these fats and their health benefits. Promotion is focused on infants, pregnant and breastfeeding mothers, those at risk for or affected by heart disease, elderly populations, as well as the general public. Consumers are spending more on functional foods and nutriceuticals, supplements, formulas with added omega-3 fats, and looking for natural ways to improve their health and lives.

Fats, structurally made of carbon chains with a carboxyl group (-COOH) and a methyl group $\left(-\mathrm{CH}_{3}\right)$ at opposite ends, are essential macronutrients for all animals. Polyunsaturated fats contain two or more double bonds unfilled with hydrogen atoms. Specific fatty acids are identified by the molecular location of the carbon double bond closest to the methyl or omega end. For humans, polyunsaturated fatty acids including dietary alpha-linolenic acid (ALA) and linoleic acid (LA) are needed from food because they cannot be synthesized by our bodies. These omega- 3 and omega- 6 fats, respectively, compete for the same enzymes necessary for their metabolism (Figure 1).

Figure 1: Linoleic acid and alpha-linolenic acid metabolism

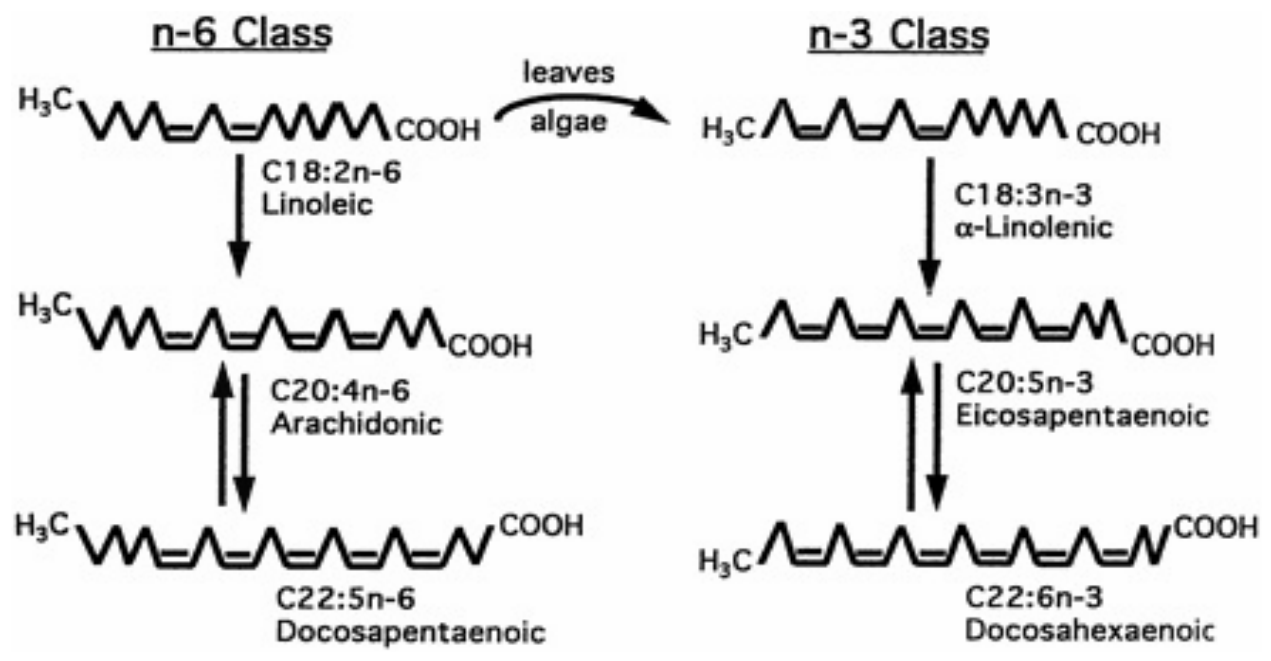


A proper ratio of omega- 3 to omega- 6 fats in the diet is important, particularly because excess omega- 6 fat intake is known to increase the risk of cardiovascular disease while omega-3 fats are known to play a role in preventing heart disease. By increasing the omega-3 fat concentration of fish through dietary modification, humans might increase their intake of these essential fats.

Omega-3 fatty acids enter the food chain and become abundant in fish for the most part through their consumption of phytoplankton, where linoleic acid can be desaturated to create ALA. Humans and fish contain dehydrogenases and desaturases that can work toward the methyl end of fats. Research has shown that trout are able to produce and store omega-3 polyunsaturated fatty acids (n-3 PUFA) upon intake of both omega-3 and omega-6 fats (Henderson 1987). After consuming shorter-chain essential fatty acids, ALA (18:3n-3) and LA (18:2n-6), fish can elongate and desaturate these to make eicosapentaenoic acid (EPA) and docosahexaenoic acid (DHA), both long chain omega-3 polyunsaturated fatty acids (Nawar 1996).

Fish feeds typically contain fish oil as their main fatty acid source. However, the demand for fish oil has been gaining, and recent worldwide plant oil production greatly exceeded that of fish oil (Hardy 2003). As plant and vegetable oils are readily available, they are a logical alternative lipid source for feed to be utilized in farmed fish. $\mathrm{Yu}$ and others $(1976,1977,1979)$ were among the first to show that different dietary lipid sources could be used with rainbow trout without affecting growth as long as required amounts of essential fatty acids were provided, including at least one percent from omega-3 fatty acids. Because fish can make EPA and DHA from ALA, a lipid source with an increased ALA concentration is promising. Comparing the fatty acids of animal 
fats, vegetable, and fish oils, flaxseed oil contains the highest percentage of ALA. Alphalinolenic fatty acids (18:3n-3) make up 53.5\% of the total fat in flaxseed oil (National Research Council 1993).

This experiment examined the effect of a diet supplemented with flaxseed oil on the total lipid content and fatty acid profile of rainbow trout (Oncorhynchus mykiss) tissue. With the Soxhlet method of lipid extraction using an organic solvent, we indirectly determined trout fat content by sample weight loss of fat and moisture removed at baseline, 1, 2, 3, and 4 months of experimental feeding. It was thought that total fat content would be unchanged by flaxseed oil dietary supplementation. However, the overall hypothesis was that supplementing the standard fat content of the trout's feed with an increased amount of flaxseed oil would lead to a higher amount of total omega-3 fatty acids, specifically EPA and DHA, in the fish. Since EPA and DHA have proven benefits to human health (Connor 2000), increasing their content in foods is of interest. It was hoped that we could develop a functional food and introduce West Virginia fish farmers to a healthier trout through dietary modification. 


\section{Review of Literature}

\section{The role of omega-3 fatty acids in human health}

Omega-three polyunsaturated fatty acids (n-3 PUFA) are publicized by many government and health organizations for their role in disease prevention and health. The American Diabetes Association recommends eating two to three servings of fish per week, citing a number of studies that show high levels of omega-3 fatty acids significantly reduce the rate of sudden death after heart attack (Gottlieb 2006). Likewise, consuming at least two fish servings, particularly fatty fish, per week is recommended by the American Heart Association (AHA). The AHA's Dietary Guidelines note reduced sudden death, decreased risk of arrhythmia, lower plasma triglyceride levels, and a reduced blood-clotting tendency as the major beneficial effects of n-3 PUFA (Krauss 2000). Supported by credible scientific evidence, the U.S. Food and Drug Administration announced the qualified health claim for reduced risk of coronary heart disease on foods that contain EPA and DHA n-3 PUFA (U.S. FDA 2004). The 2005 Dietary Guidelines for Americans also note the association between consumption of fatty acids in fish and reduced risks of mortality from cardiovascular disease for the general population (USDA and HHS 2005).

Studies have linked the anti-inflammatory effect of n-3 PUFA to reduce the risk of coronary artery disease (CAD), strokes, autoimmune disorders such as lupus and nephropathy, and relapses in those affected with inflammatory bowel disorders, particularly Crohn's disease (Connor 2000). Additionally, researchers are investigating the effects of n-3 PUFA on mild hypertension, lung disease, diabetes and glucose control, and rheumatoid arthritis (Sinclair 2000). 
Cardiovascular disease (CVD) is the number one cause of death in the United States, and diet has a role in its prevention. A number of epidemiological studies have examined the role of fish consumption in preventing CVD. Using fish intake from a detailed dietary history of 1,822 men in the Chicago Western Electric Study, Daviglus (1997) looked at the causes of death as related to CAD in a 30-year follow-up study. The data showed a significant inverse relationship between fish consumption and death from CAD, particularly non-sudden death from a myocardial infarction (MI). Those who consumed $35 \mathrm{~g}$ or more of fish per day compared with those who ate none had relative risks of death from CAD and from MI of 0.62 and 0.56 ( $\mathrm{p}$ for trend $=0.04$ and 0.02 ), respectively. Omega-3 fatty acids likely played a role in the outcome; however, it should not be assumed that the benefits of increased fish consumption were a result of n-3 PUFA alone.

When investigating the cardio-protective benefits of eating fish, specific n-3 PUFA intake must be accounted. In 2002, Hu and others sought to examine the association between fish and n-3 PUFA consumption and risk of CAD in women in the Nurses' Health Study. This sixteen year follow-up study used validated dietary consumption questionnaires from 84,688 female nurses. After adjusting for age, smoking, and other cardiovascular risk factors, the relative risks of CAD were 0.79 for fish consumption one to three times per month, 0.71 for once per week, 0.69 for two to four times per week, and 0.66 for five or more times per week ( $p$ for trend $=0.001$ ). To estimate n-3 PUFA intake, the researchers used mean values of each fish type reported from the U.S. Department of Commerce's 1984 data. A similar inverse relationship was found across quintiles of n-3 PUFA intake. As n-3 PUFA intake increased, women had 
lower CAD risk with multivariable relative risks of $1.0,0.93,0.78,0.68$, and 0.67

$(\mathrm{p}<.001$ for trend). Additionally, the reduction in risk for women who ate fish 5 or more times per week was stronger for CAD deaths than for nonfatal myocardial infarction, as multivariate relative risks were 0.55 and 0.73 , respectively. Hu's study was one of the first to provide information regarding n-3 PUFA intake and CAD risk among women. Overall, $\mathrm{Hu}$ found that women with a higher intake of fish and n-3 PUFA had a lower risk of $\mathrm{CAD}$, particularly death due to $\mathrm{CAD}$, compared with those who ate fish less than once per month.

To illustrate the cardio-protective effect n-3 PUFA among men, researchers compared the effects of consuming fatty and lean fish on CAD mortality (Oomen 2000). Using diet information from 1,088 Finnish, 1,097 Italian, and 553 Dutch men in the Seven Countries Study, fish intake was classified into two groups based on the fat content of the type of fish recorded. After adjusting for such factors as age, body mass index, smoking, energy intake, and relevant dietary variables, these authors found that fatty fish consumption was associated with lower CAD mortality in 20 years of follow-up. Among those who ate fatty fish, the pooled relative risk was 0.66 . The results suggest that the type of fish should be considered for protecting against CAD death, as eating fish with more fat might be healthier.

From the Physician's Health Study in the United States, fish and n-3 PUFA consumption were compared with the risk of sudden cardiac death in 20,551 male physicians followed for 11 years (Albert 1998). Eating fish once per week was associated with a $52 \%$ lower risk of sudden cardiac death compared with consuming fish less than monthly $(\mathrm{p}=0.04)$. Estimated dietary n-3 PUFA intake from seafood, varying 
from 0.3 to 2.7 grams per month, was also associated with a reduction in sudden cardiac death. However, there were not significant trends in reduction as fish intake or n-3 PUFA intake increased greater than once a week. This suggests a threshold effect, and additional research is warranted into the dose effects of eating fish more than once a week.

Additionally, the specific type of fat consumed is of importance. Studies have linked ALA intake with lower cardiac event and disease risks. In the Health Professionals' Study, researchers measured the relationship between ALA and myocardial infarction (MI) incidence among men (Ascherio 1996). From food-frequency questionnaires, ALA intake ranged from 0.7 to $0.8 \mathrm{~g} /$ day to 1.4 to $1.5 \mathrm{~g} /$ day. The study revealed that a $1 \%$ increase in ALA intake was associated with a 0.41 relative risk for acute MI ( $\mathrm{p}$ for trend $=0.01)$. The National Heart, Lung, and Blood Institute Family Heart Study also determined that ALA was inversely related to CAD (Djousse 2001).

\section{The ratio between omega- 3 and omega- 6 fatty acids and the Western diet}

The mechanisms of action attributed to the effects of n-3 PUFA on cardiovascular disease are not specifically known. However, eicosanoids, including prostaglandins, prostacyclins, lipoxins, thromboxanes, and leukotrienes, from EPA have localized effects in the body, and DHA is a vital component of cell membrane phospholipids in all body tissues. DHA is especially important in the brain and retina (Connor 2000). EPA and DHA hold antiarrhythmic, antiinflammatory, antithrombogenic, and hypotriglyceridemic properties. They also retard atherosclerotic plaque growth and are mildly hypotensive.

There is no Recommended Daily Allowance for n-3 PUFA intake. It should be noted that the FDA recommends n-3 PUFA consumption not exceed 3 grams per day 
from all food sources due to risks of excessive bleeding. Based on ALA, daily adequate intake levels for n-3 PUFA are set by the Institute of Medicine and the Food and Nutrition Board at $1.6 \mathrm{~g}$ for men and $1.1 \mathrm{~g}$ for women (2002). An average of $0.65 \mathrm{~g} /$ day of EPA and DHA combined has been suggested (Harvard Medical School Health 2002).

Although n-6 PUFA are essential for humans, excess intake can increase the risk of cardiovascular disease (Baylin 2004). Linoleic acid (C18:2n-6) is metabolized to arachidonic acid. The eicosanoids derived from AA are proinflammatory and proaggregatory, having a role in the body's inflamatory reactions and vascular disease by way of platelet aggregation. For this reason, the proper ratio of n-6 to n-3 PUFA in the diet is important. More specifically, the ratio of AA to DHA may also be notable.

Using epidemiological data over the past 40 years, researchers in Japan associated allergic patients and cancer mortalities with an increased n-6 to n-3 PUFA intake ratio from 2.8 to about 4 (Okuyama 1997). An n-6/n-3 PUFA ratio of 2 or below was recommended to help suppress aging, carcinogenesis, and atherosclerosis.

An increase in fish consumption, along with other n-3 PUFA food sources, helps decrease the n-6/n-3 ratio. It is important to note that frying, particularly deep-frying, fish introduces n-6 and possibly trans-saturated fatty acids and may thereby increase CVD risk. Omega-3 fortified products such as eggs and bread have been developed to help increase the intake of n-3 PUFA, and these foods appear to be more common to Western population diets compared to fish. However, health organizations' campaigns for regular fish consumption combined with increased fears of avian influenza and "mad cow" disease may create a higher market for fish. 


\section{Efforts to increase EPA and DHA in fish}

The effects of various dietary fats on the fatty acid content of commercially raised fish is of both financial and health interest. Increasing the lipid concentration of trout can be achieved with either animal or vegetable oils. Administering a diet consisting of $30 \%$ lipid from menhaden fish oil, Chaiyapechara and others (2003) were able to produce rainbow trout with significantly heavier weight and weight gain compared to those fed a $10 \%, 15 \%$, or $20 \%$ lipid equivalent diet. Fish that were fed the $30 \%$ lipid diet had a significantly higher fillet lipid concentration than did trout that consumed a $10 \%$ or $15 \%$ lipid diet. Feed conversion ratio (FCR) was determined by dividing the weight of dry feed consumed by the body weight gained for the fish in each particular feeding group. Those fed the $30 \%$ fat diet had a significantly lower FCR than the $10 \%$ and $15 \%$ treatment groups. Lipid oxidation by way of thiobarbituric acid reactive substances (TBARS) tests at 3 and 10 days post-harvest in $5^{\circ} \mathrm{C}$ storage and week 8 and 12 at $-20^{\circ} \mathrm{C}$ did not indicate any significant differences among treatments, although observed values of lipid oxidation increased over time.

Similarly, rainbow trout fed a diet reformulated with menhaden oil to contain $45 \%$ protein and $16 \%$ fat had significantly higher levels of fat and percentages of $n-3$ PUFA than those fed a control diet containing $45 \%$ protein and $12 \%$ fat after a nine-week trial (Turner 1990). Fish fed the higher fat diet had almost 43\% more total n-3 PUFA per gram of fillet. The differences became significant during the fourth week of experimentation. With similar mortality rates, both groups appeared healthy and growth was not affected. 
In studies comparing lipid sources, feeds supplemented with flaxseed oil have been shown to increase the n-3 PUFA concentration of trout tissue. Greene and Selivonchick (1990) contrasted salmon oil, soybean oil, flaxseed oil, chicken fat, pork lard, and beef tallow as lipid components of rainbow trout diets. The trout were fed a diet commonly used by hatcheries that contained $6 \%$ fat supplied by marine oil until the trout reached 11 months of age. Experimental diets with the $6 \%$ fat replaced by alternate lipid sources were then fed to duplicate groups of 50 fish per tank for 20 weeks. Fish were fed twice daily on weekdays to apparent satiation and fasted over the weekends. Dissolved oxygen concentration varied from 9.5 to $10.0 \mathrm{ppm}$ during the study. Diets were stored at $-34.4^{\circ} \mathrm{C}$ and removed as needed for feeding. Fish were fasted for three days prior to selection and obtaining fillets. Tissue analysis of fatty acids via gas chromatography indicated the highest percent of total n-3 fatty acids (Table 1) among trout fed the flaxseed oil diet.

Table 1: Fatty acid composition of trout muscle (wt \%) from feeding a flaxseed oil diet Data are given as mean \pm standard deviation of 24 chromatographs, with methyl ester samples for 12 fish run in duplicate.

\begin{tabular}{|c|c|c|c|}
\hline Total n-3 & ALA & DHA & EPA \\
\hline 30.29 & $14.27 \pm 1.21$ & $9.81 \pm 1.61$ & $2.03 \pm 0.19$ \\
\hline
\end{tabular}

The results were attributed to unaltered ALA deposited from the flaxseed diet, which contained the highest percentage of total $\mathrm{n}-3$ fats (34.13\%) and ALA (25.81\%). EPA was found to be $2.03 \%$ and DHA $9.81 \%$ of total fatty acids in trout muscle tissue, combined to give $11.84 \% \mathrm{EPA}+\mathrm{DHA}$. This amount was similar to the percentages of other test diets except the trout fed salmon oil that had $18.0 \%$ of total fats as EPA + DHA. The researchers concluded that trout fed a flaxseed oil diet reached an adequate level of EPA 
+ DHA compared to the other experimental diets with alternate lipid sources. Because the long chain products of ALA were not higher among the flaxseed oil trout, they suggested trout are not able to oxidize dietary ALA in excess of metabolically optimum levels. A level of $8-10 \%$ DHA was considered the optimum for rainbow trout muscle raised under their experimental conditions, and further studies were recommended.

Recently, researchers compared the effect of adding flaxseed and sunflower oil to rainbow trout feed on the fatty acid content of trout fillets (Komprda 2005). Although the values were not statistically evaluated, deposited n-3 PUFA (ALA + EPA + DHA) among trout fed the diet with sunflower oil was unexpectedly higher than trout fed the diet with flaxseed oil. Although sunflower oil contains a higher n-6/n-3 ratio than flaxseed oil, it was asserted that the trout fed sunflower oil more efficiently transferred the n-3 PUFA from the diet to their tissue. The EPA +DHA percentage in all tissues decreased significantly $(\mathrm{p}<0.001)$ with increasing fat content.

Further investigation is necessary to determine the ideal trout diet lipid source and quantity in order to produce increased n-3 PUFA concentration without influencing other biological factors. 


\section{Statement of the Problem}

Omega-3 fatty acids are beneficial to human health for a variety of reasons, particularly in helping reduce cardiovascular disease risks. Therefore, it is important that we increase consumption of these in our diet. Most Americans do not eat enough foods that are high in EPA and DHA and have an increased consumption of vegetable oils rich in n-6 fatty acids. Kris-Etherton and others (2000) found the daily intake of ALA in the United States to be approximately $1.4 \mathrm{~g}$, with just 0.1 to $0.2 \mathrm{~g}$ coming from EPA and DHA. This is less than a third of the recommended $0.65 \mathrm{~g} /$ day of EPA and DHA. Although some ALA is converted to the longer chain n-3 PUFA, the amount appears limited.

All fish contain EPA and DHA, but the quantities vary among species and within a species. Researchers have shown that eating fish at least once a week and increasing n3 PUFA intake protect against cardiac events and death in males and females. Similarly, health and U.S. government agencies recommend consuming at least two fish servings, particularly fatty fish, weekly.

Increasing the n-3 PUFA concentration of farm-raised fish is possible by changing the fatty acid profile of the diet. By using flaxseed oil as a component of fish diets to create omega-3 fortified rainbow trout, a functional food could be marketed to help achieve an adequate n-3 PUFA intake and promote good health. West Virginia's aquaculture industry could apply our feeding technique to their practices and possibly increase sales profits while improving the health status of those who consume n-3 PUFA fortified trout. 


\section{Materials and Methods}

\section{Experimental design}

The experiment was conducted at Reymann Memorial Farm in Hardy County, WV, where a honeycomb fiber reinforced polymer raceway system was in place. This facility, part of the WV Agricultural Experiment Station, was exposed to the natural environment and climate of West Virginia's eastern panhandle. A nearby spring supplied the water, which was piped into a distribution box where an electric aerator provided continuous aeration to maintain dissolved oxygen level at $70 \%$ saturation or more. The two adjacent raceways had four levels each; every level was ten inches lower than the previous level to facilitate water flow. A quiescent zone was located at the end of each level. Waste was removed through drains in the quiescent zone and collected in two cone bottom tanks. Water accumulated at the end of the system in a collection box and flowed into a nearby pond.

Half inch mesh screens were placed in the system to create a total of forty experimental units to facilitate a randomized complete block design with each diet being tested in quadruplicate. Quarter inch mesh hardware cloth was attached to the screens to keep feed pellets in their particular unit. Netting was placed over the raceway so that the fish could not jump out of their assigned unit, and it also prevented fish removed by predatory animals. 


\section{Rainbow trout and diets}

Seventy-five rainbow trout, approximately 10 inches total length, were stocked in each of the 36 experimental units. They were fed a Grower-standard diet known as Zeigler Gold (Table 2) for one week. Trout and feed samples were taken on November 21, 2003, beginning the feeding trial experiment. Formulated by Zeigler Brothers, Inc. to our requested specifications, the diets were supplemented with 0,15 , and $23.5 \%$ of flaxseed oil to partially replace the fat in the standard diet and vitamin E (dl-alphatocopheryl acetate) at 0,300 , and $1500 \mathrm{mg} / \mathrm{kg}$ of feed. They used a base diet, containing $6.1 \%$ fat without any fat supplementation, and added $7.77 \%$ fat before extrusion. The remainder of the flaxseed oil was sprayed on to the product. As the original plan was to have a higher fat diet, the $23.5 \%$ flaxseed oil supplementation represented the maximum amount that the Zeigler feed mill could add to the diet.

Nine different diets were used, with each randomly assigned to a color and experimental unit to achieve a blind study (Table 3). By using the four level raceway system, the study was replicated four times. For four months, equal amounts of the corresponding feed were placed daily in each unit. Feed was was stored at $4{ }^{\circ} \mathrm{C}$ and removed as needed for feeding. 
Table 2: “Zeigler Gold” Grower-standard pellet diet supplied and reported by Ziegler Brothers, Inc. (Gardners, PA)

\begin{tabular}{|c|c|c|}
\hline PROTEIN & $\%$ & 44.2700 \\
\hline ARGININE & $\%$ & 2.5843 \\
\hline LYSINE & $\%$ & 2.4206 \\
\hline METHIONINE & $\%$ & 0.8984 \\
\hline CYSTINE & $\%$ & 0.8194 \\
\hline FAT & $\%$ & 15.8889 \\
\hline CRUDE FIBER & $\%$ & 2.5561 \\
\hline $\mathrm{ASH}$ & $\%$ & 7.2251 \\
\hline CALCIUM & $\%$ & 1.4926 \\
\hline PHOS TOTAL & $\%$ & 1.1663 \\
\hline SODIUM & $\%$ & 0.2090 \\
\hline POTASSIUM & $\%$ & 0.5247 \\
\hline CHLORINE & $\%$ & 0.2007 \\
\hline MAGNESIUM & $\%$ & 0.1353 \\
\hline SULFUR & $\%$ & 0.4811 \\
\hline MANGANESE & PPM & 80.4902 \\
\hline ZINC & PPM & 103.4818 \\
\hline IRON & PPM & 380.2087 \\
\hline COPPER & PPM & 13.2350 \\
\hline COBALT & PPM & 0.7608 \\
\hline IODINE & PPM & 1.4330 \\
\hline SELENIUM & PPM & 1.2247 \\
\hline MOISTURE & $\%$ & 8.7100 \\
\hline NFE & $\%$ & 25.9462 \\
\hline VITAMIN A & $\mathrm{KIU} / \mathrm{KG}$ & 16.6920 \\
\hline VITAMIN D3 & $\mathrm{KIU} / \mathrm{KG}$ & 4.5384 \\
\hline VITAMIN E & IU/KG & 243.7087 \\
\hline VITAMIN K & PPM & 15.3325 \\
\hline THIAMINE & PPM & 57.0184 \\
\hline RIBOFLAVIN & PPM & 72.0767 \\
\hline NIACIN & PPM & 410.9633 \\
\hline PANTOTHENIC ACID & PPM & 171.4826 \\
\hline CHOLINE & PPM & $2,756.3600$ \\
\hline PYRIDOXINE & PPM & 57.4627 \\
\hline FOLACIN & PPM & 19.4599 \\
\hline BIOTIN & PPM & 1.4466 \\
\hline VITAMIN B12 & PPB & 127.4902 \\
\hline ASC ACID/ASPP & PPM & 257.2500 \\
\hline
\end{tabular}


Table 3: Raceway Designation and Experimental Diets

\begin{tabular}{|l|r|}
\multicolumn{1}{|c|}{$\mathrm{H}_{2} \mathrm{O}$} \\
\hline $6 \mathrm{Y}$ & $\mathbf{1} \mathrm{GR}$ \\
\hline $7 \mathrm{BR}$ & $\mathbf{2 ~ W}$ \\
\hline $8 \mathrm{O}$ & \\
\hline $\mathbf{9 ~ P}$ & $4 \mathbf{R}$ \\
\hline $\mathbf{1 0} \mathrm{BL}$ & $\mathbf{5} \mathbf{~ B L K}$ \\
\hline \multicolumn{2}{|c|}{ QZ } \\
\hline
\end{tabular}

\begin{tabular}{|l|c|}
\hline $16 \mathrm{O}$ & \\
\hline $17 \mathrm{BR}$ & $12 \mathrm{R}$ \\
\hline $18 \mathrm{Y}$ & $13 \mathrm{P}$ \\
\hline $19 \mathrm{~W}$ & $14 \mathrm{G}$ \\
\hline $20 \mathrm{BL}$ & $15 \mathrm{BLK}$ \\
\hline \multicolumn{2}{|c|}{ QZ } \\
\hline
\end{tabular}

\begin{tabular}{|l|c|}
\hline $26 \mathrm{BR}$ & $21 \mathrm{BLK}$ \\
\hline $27 \mathrm{BL}$ & $22 \mathrm{Y}$ \\
\hline $28 \mathrm{R}$ & $23 \mathrm{~W}$ \\
\hline $29 \mathrm{P}$ & \\
\hline $30 \mathrm{G}$ & $25 \mathrm{O}$ \\
\hline \multicolumn{2}{|c|}{$\mathbf{Q Z}$} \\
\hline
\end{tabular}

\begin{tabular}{|l|r|}
\hline & $31 \mathrm{BLK}$ \\
\hline $37 \mathrm{R}$ & $32 \mathrm{BL}$ \\
\hline $38 \mathrm{~W}$ & $33 \mathrm{P}$ \\
\hline $39 \mathrm{BR}$ & $34 \mathrm{O}$ \\
\hline $40 \mathrm{G}$ & $35 \mathrm{Y}$ \\
\hline \multicolumn{2}{|c|}{$\mathbf{Q Z}$} \\
\hline
\end{tabular}

\begin{tabular}{|c|c|c|c|}
\hline $\begin{array}{c}\text { \% FLAXSEED } \\
\text { OIL }\end{array}$ & VIT. $\mathbf{E}$ & COLOR & ABBREVIATION \\
\hline \multirow{2}{*}{$\begin{array}{c}0 \\
\text { (Basal) }\end{array}$} & 0 & RED & $\mathrm{R}$ \\
\cline { 2 - 4 } & 300 & YELLOW & Y \\
\cline { 2 - 4 } & 1500 & BLUE & BL \\
\hline \multirow{4}{*}{15} & 0 & GREEN & G \\
\cline { 2 - 4 } & 300 & BLACK & BLK \\
\cline { 2 - 4 } & 1500 & ORANGE & O \\
\hline \multirow{4}{*}{23.5} & 0 & WHITE & W \\
\cline { 2 - 4 } & 300 & BROWN & BR \\
\cline { 2 - 4 } & 1500 & PURPLE & P \\
\hline
\end{tabular}

$\mathrm{QZ}=$ Quiescent zone

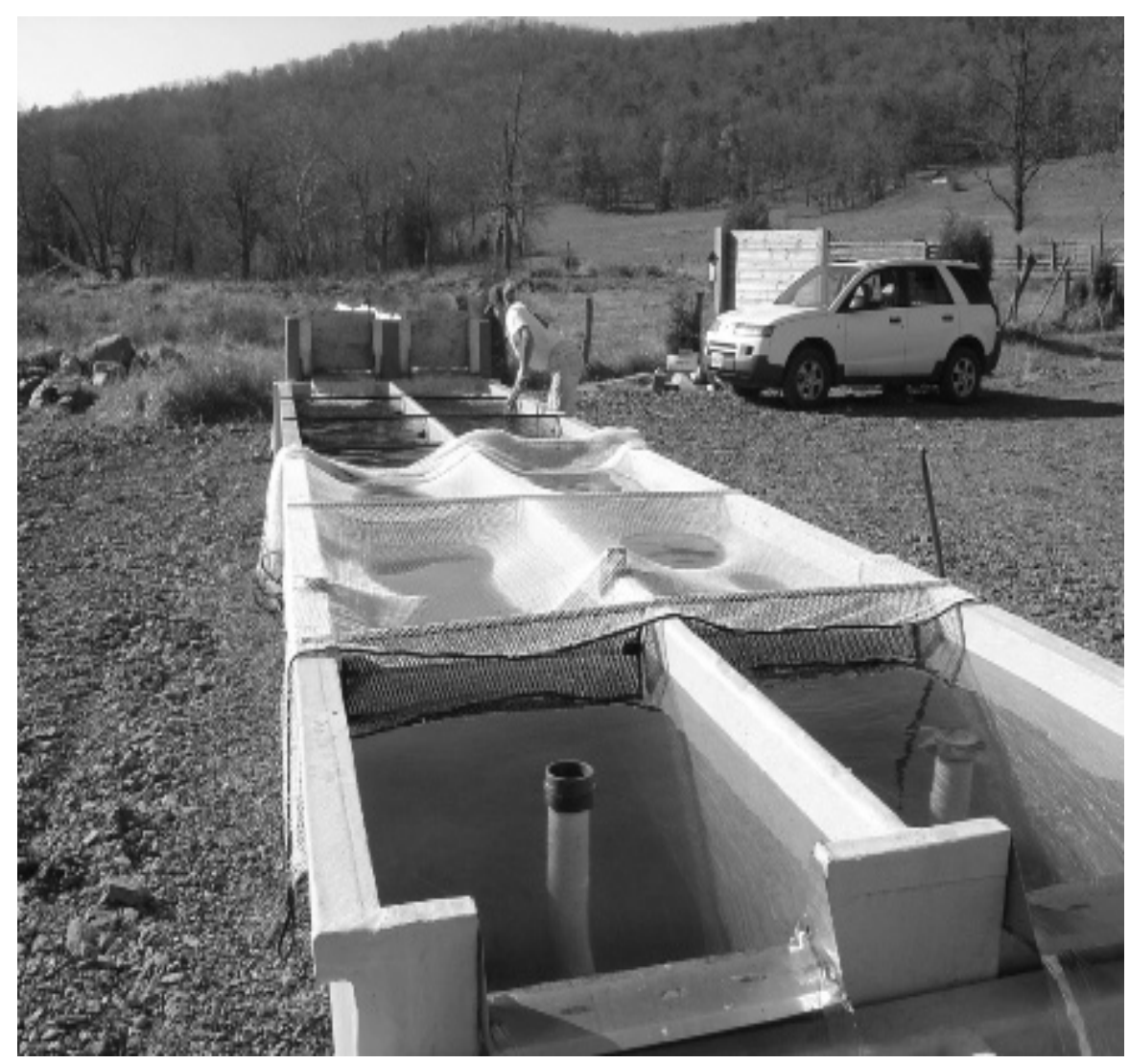




\section{Sample selection}

Samples for fat analyses were obtained by netting a single fish taken from each of 36 experimental units at $0,1,2,3$, and 4 months of feeding. After being caught with a dip net, they were immobilized via a blow to the head with PVC piping. Trout and experimental diet samples were appropriately marked and tagged, placed in iced coolers, transferred to the lab facilities in Morgantown, WV, and subsequently prepared for analysis. Transit time did not exceed 3.5 hours. Animal handling protocol was approved by the West Virginia University's Animal Care and Use Committee was followed throughout our fish feeding experiment

\section{Sample preparation and moisture assay}

The 36 fish were immediately processed to obtain two butterfly fillets per sample and rinsed under cold tap water to remove blood and waste. Then, they were both patted dry and ground in a Waring commercial blender (model 51BL31) to achieve a homogenous mixture of paste consistency. Next, the samples were divided into separately marked bags for various analyses. Moisture content assays were performed the night of each harvest (AOAC 1990). Three samples (2 g each) from each experimental unit were weighed in previously heat dried and cooled aluminum tins and placed in an oven set at $105^{\circ} \mathrm{C}$ for $15-16$ hours. Then, they were allowed to cool in a desiccator with reignited $\mathrm{CaO}$ and re-weighed. Weight differences were calculated to determine the average moisture content. The remaining samples were frozen at $-80^{\circ} \mathrm{C}$ in an ultra low temperature freezer (New Brunswick Scientific, model U535-86) to be subsequently tested. Fish from each month were similarly prepared, partially thawed, and tested. 


\section{Lipid measurements:}

Fatty acid profile

Total lipid extraction and purification was completed using methodology described by Bligh and Dyer (1959). Homogenized trout muscle $(0.5 \mathrm{~g})$ and $5 \mathrm{ml}$ Trizma/EDTA buffer were added to a centrifuge tube and vortexed for 60 seconds. Then, $20 \mathrm{ml}$ of chloroform:absolute methanol:glacial acetic acid at a volumetric ratio of 2:1:0.015 was added and vortexed twice. Tubes were held at room temperature for 10 min and then centrifuged at $4000 \mathrm{rpm}$ for 10 minutes at $10^{\circ} \mathrm{C}$. The lower layer was transferred with a Pasteur pipette into a filter and collected in a separate centrifuge tube. Next, $10 \mathrm{ml}$ of 4:1 chloroform:methanol was added to the remaining upper layer, vortexed, and centrifuged in the same fashion. The entire lower layer was transferred out again and filtered. Filter papers and the funnel were rinsed with $5 \mathrm{ml}$ 2:1

chloroform:methanol. The tubes were placed in a $60^{\circ} \mathrm{C}$ water bath while the filtered samples were dried for 1 hour under nitrogen gas.

Four $\mathrm{ml}$ of $\mathrm{H}_{2} \mathrm{SO}_{4}$ was then added, caps were tightened, and the tubes heated in a $90{ }^{\circ} \mathrm{C}$ water bath for 1 hour. After cooling in cold tap water, $3 \mathrm{ml}$ of distilled, deionized water and $8 \mathrm{ml}$ of chloroform were added. Tubes were again vortexed and centrifuged as previously described. The bottom chloroform layer was transferred through a $\mathrm{Na}_{2} \mathrm{SO}_{4}$ filled Pasteur pipette into a $10 \mathrm{ml}$ glass tube, using chloroform to wash out any sample trapped in the filter. Again, the tubes were placed in a $60^{\circ} \mathrm{C}$ water bath and blown under nitrogen gas for 20-25 min until the samples were completely dried. Samples were resuspended in $3 \mathrm{ml}$ of filtered isooctane and injected into a syringe. Fatty acid profile (FAP) was determined using a gas chromatograph (Varian CP-3800) according to the 
procedures of Greene and Selivonchick (1990). Comparing the retention times with known standards and references (Ackman 1980), the fatty acids were identified. The peaks were integrated and the concentration of fatty acids calculated using the Star GC workstation version 6 software (Varian Analytical Instruments).

Soxhlet fat extraction

Soxhlet extraction was performed to determine the total lipid contents of the trout fillets and feed (AOAC 920.39, 1995). A 5-gram homogenized trout muscle sample was weighed onto an oven-dried filter paper. The paper sides were folded up and fastened with a paper clip to form a pouch to hold the sample in place. Eight samples were placed in each extractor. Petroleum ether was added to the extractors to submerge the samples. The apparatuses were connected together tightly, and the condensers were fitted with rubber tubing. Flasks were electrically heated 14-16 hours overnight at a rate so that the petroleum ether was gently boiling. The apparatus was disconnected and residual petroleum ether was decanted from the extractor. Samples were removed and allowed to air dry under a hood for 4 hours, after which paper clips were removed. Finally, the samples were dried in an oven at $105^{\circ} \mathrm{C}$ for 8 hours, cooled in a desiccator, and reweighed. Calculations for the crude fat percent were determined as follows: $\%$ crude fat $=(($ weight of flask + fat $)-$ weight of empty flask $) /$ weight of sample $\times 100$

\section{Statistical analysis}

Group fat percent means were calculated for the three dietary treatments at baseline, 1, 2, 3, and 4 months. Significant differences between groups were tested using one-way analyses of variance (ANOVA). These tests were performed using SAS 8.00 (SAS Institute, Cary, NC, 1999). 


\section{Results}

The $23.5 \%$ flaxseed oil diet contained the highest concentration of total n-3 PUFA and ALA $(\mathrm{P}<0.05)$ and the lowest DHA and EPA content (Table 4).

Table 4: Fatty acid composition of experimental diets

Parameter

Basal
Treatment

$15 \% \mathrm{FO}$

$23.5 \% \mathrm{FO}$

fatty acid (\%) in total fatty acids

$\begin{array}{cccc}\text { ALA }(18: 3 n-3) & 3.47 \pm 1.14 \mathrm{c} & 33.30 \pm 2.98 \mathrm{~b} & 46.22 \pm 1.89 \mathrm{a} \\ \text { EPA }(20: 5 \mathrm{n}-3) & 10.93 \pm 0.64 \mathrm{a} & 2.87 \pm 0.52 \mathrm{~b} & 1.22 \pm 0.32 \mathrm{c} \\ \text { DHA }(22: 6 \mathrm{n}-3) & 12.72 \pm 0.77 \mathrm{a} & 3.68 \pm 0.60 \mathrm{~b} & 1.62 \pm 0.15 \mathrm{c} \\ \text { Total } \mathrm{n}-3 & 27.47 \pm 1.44 \mathrm{c} & 40.08 \pm 2.07 \mathrm{~b} & 49.07 \pm 2.13 \mathrm{a}\end{array}$

Data are given as mean \pm SEM $(n=6)$. Mean values in a horizontal row with different letters were significantly different $(\mathrm{P}<0.05)$.

There were no significant differences $(\mathrm{P}>0.05)$ among the moisture or total fat contents (Table 5) of rainbow trout fillets due to supplementing the basal diet with flaxseed oil throughout the 120 days of experimental feeding. The total fat variation of 1.91 to $5.11 \%$ at day 0 (baseline) is problematic as values were expected to be similar. Trout were obtained from a private grower and thought to be uniform in age and treatment. 
Table 5: Total fat (\%) of trout fillets as affected by supplementing feed with flaxseed oil (FO)

Feeding period (Days)

\author{
Treatment
}

$\begin{array}{cccc} & \text { Basal } & 15 \% \text { FO } & 23.5 \% \text { FO } \\ 0 & -1.91 \pm 0.80 & 3.79 \pm 1.15 & 5.11 \pm 1.37 \\ 30 & 2.66 \pm 0.31 & 2.31 \pm 0.51 & 3.87 \pm 0.76 \\ 60 & 4.29 \pm 0.70 & 4.48 \pm 0.98 & 5.85 \pm 1.30 \\ 90 & 3.83 \pm 0.75 & 4.70 \pm 1.14 & 4.09 \pm 0.47 \\ 120 & 2.04 \pm 0.43 & 2.13 \pm 1.19 & 1.83 \pm 0.45\end{array}$

Data are given as mean $\pm \operatorname{SEM}(\mathrm{n}=12)$. Values are given as $\%$ by weight on dry basis.

Fatty acid profile analyses (Table 6) revealed the highest concentration of total n3 PUFA in the $23.5 \%$ FO group $(\mathrm{P}<0.05)$, followed by the $15 \%$ FO group, and the control group. However, both EPA and DHA contents significantly decreased as the feeding trial progressed $(\mathrm{P}<0.05)$. The lowest $(\mathrm{P}<0.05)$ proportion of saturated fatty acids was obtained in $23.5 \%$ FO group, followed by $15 \%$ FO group and control group. Conversely, the amount of total unsaturated fatty acid was highest in the $23.5 \% \mathrm{FO}$ group, followed by $15 \% \mathrm{FO}$ group and control group. The results indicate that n-3 PUFA enhanced trout can be raised by feeding diets supplemented with flaxseed oil. 
Table 6: Fatty acid profile in trout fillets as affected by feed supplementation with flaxseed oil

\begin{tabular}{|c|c|c|c|c|}
\hline \multirow[b]{2}{*}{ Parameters (\%) } & \multirow{2}{*}{$\begin{array}{c}\text { Feeding } \\
\text { (Days) }\end{array}$} & \multicolumn{3}{|c|}{ Treatment } \\
\hline & & Rasal & $15 \% \mathrm{FO}$ & $235 \% \mathrm{FO}$ \\
\hline \multirow[t]{5}{*}{ Saturated fatty acid } & $\mathbf{0}$ & 31.38 & 26.93 & 33.31 \\
\hline & 30 & 33.38 a & 30.44 ah & $27.79 \mathrm{~h}$ \\
\hline & 60 & 32.88 a & $27.66 \mathrm{~h}$ & $24.60 \mathrm{~h}$ \\
\hline & 90 & 40.21 a & $33.15 \mathrm{~h}$ & $21.97 \mathrm{c}$ \\
\hline & 120 & $35.63 \mathrm{a}$ & $34.35 \mathrm{a}$ & $24.75 b$ \\
\hline \multirow[t]{5}{*}{ Unsaturated fatty acid } & 0 & 68.62 ah & 72.73 a & $66.69 \mathrm{~h}$ \\
\hline & 30 & $66.63 \mathrm{~h}$ & $69.56 \mathrm{ah}$ & 72.21 a \\
\hline & 60 & $67.12 \mathrm{~h}$ & 72.34 a & 75.40 a \\
\hline & 90 & 59.79 c & $66.85 \mathrm{~h}$ & 78.03 a \\
\hline & 120 & $64.38 \mathrm{~b}$ & $65.66 \mathrm{~b}$ & $75.25 \mathrm{a}$ \\
\hline \multirow[t]{5}{*}{ Omega-3 (n-3) fatty acids } & $\mathbf{0}$ & 29.13 & 30.96 & 28.09 \\
\hline & 30 & $35.79 \mathrm{~h}$ & $34.84 \mathrm{~h}$ & 42.76 a \\
\hline & 60 & $31.08 \mathrm{c}$ & $35.64 \mathrm{~h}$ & 40.48 a \\
\hline & 90 & $34.18 \mathrm{c}$ & $37.61 \mathrm{~b}$ & 41.79 a \\
\hline & 120 & $24.66 \mathrm{~b}$ & $25.74 b$ & $39.37 \mathrm{a}$ \\
\hline \multirow[t]{5}{*}{ ALA (18:3n3) } & 0 & 2.04 & 2.11 & 1.92 \\
\hline & 30 & $5.46 \mathrm{c}$ & $10.18 \mathrm{~h}$ & 17.64 a \\
\hline & 60 & $5.29 \mathrm{c}$ & $15.90 \mathrm{~h}$ & 23.33 a \\
\hline & 90 & $6.29 \mathrm{c}$ & $17.28 \mathrm{~h}$ & 25.92 a \\
\hline & 120 & $2.63 \mathrm{c}$ & $14.73 \mathrm{~b}$ & $26.66 \mathrm{a}$ \\
\hline \multirow[t]{5}{*}{ EPA $(20: 5 n 3)$} & 0 & 6.23 & 6.43 & 5.94 \\
\hline & 30 & 6.51 a & $5.01 \mathrm{~h}$ & $4.91 \mathrm{~h}$ \\
\hline & 60 & 5.74 a & $3.62 \mathrm{~h}$ & $3.42 \mathrm{~h}$ \\
\hline & 90 & 6.49 a & $3.80 \mathrm{~h}$ & $3.31 \mathrm{~h}$ \\
\hline & 120 & $4.74 a$ & $2.31 \mathrm{~b}$ & $2.62 \mathrm{~b}$ \\
\hline \multirow[t]{5}{*}{ DHA (22:6n3) } & 0 & 20.75 & 22.42 & 20.23 \\
\hline & 30 & 23.38 a & $18.89 \mathrm{~h}$ & $19.40 \mathrm{~h}$ \\
\hline & 60 & 19.48 a & $15.18 \mathrm{~h}$ & $12.84 \mathrm{~h}$ \\
\hline & 90 & 20.62 a & $15.24 \mathrm{~h}$ & $11.64 \mathrm{c}$ \\
\hline & 120 & 16.70 a & 9.05 h & $7.94 \mathrm{~h}$ \\
\hline
\end{tabular}


The increased concentration of total omega-3 fatty acids in the supplemental FO groups was due to the increased concentration of ALA $(\mathrm{P}<0.05)$. After the first month of supplemental diet, ALA concentrations increased and continued to more steadily rise over the next three months (Figure 2).

Figure 2: \% ALA of total fatty acids in trout fillets as affected by feed supplementation with $23.5 \%$ flaxseed oil $(n=12)$

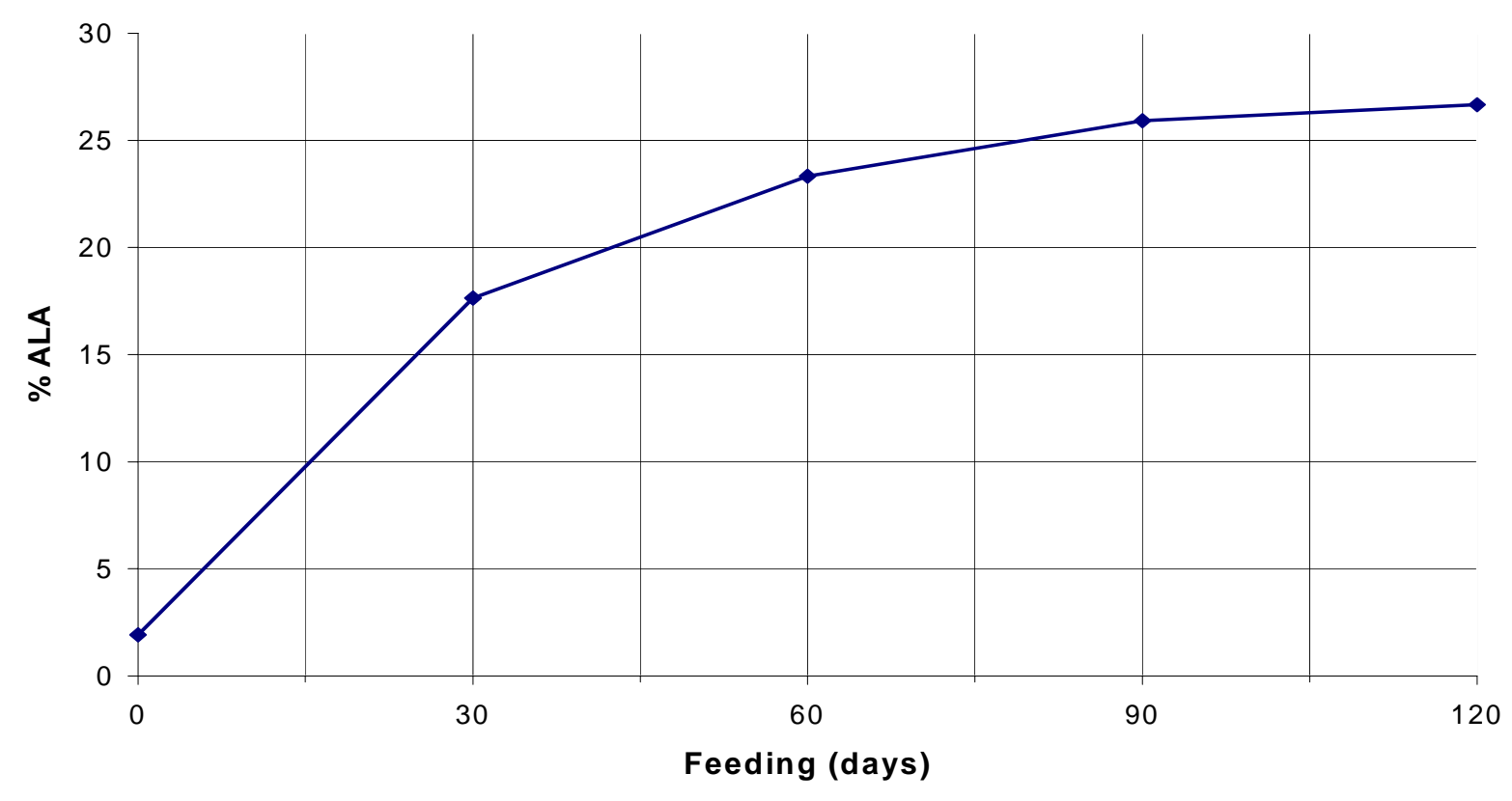




\section{Discussion}

Supplementing the rainbow trout diets with flaxseed oil significantly increased the concentration of ALA in the trout fillets. It appears that the fatty acid profiles of rainbow trout reflect that of their lipid source, as flaxseed oil contains the highest percentage of ALA among fatty acids. Because only two concentrations of dietary fat (15 and 23.5\%) were tested in this study, the effects of more varied fat concentrations should be examined. Just as the ratio of n-6/n-3 PUFA is key to human diets, it is likely vital to fish feeds and might be evaluated in future experiments. Given our results, using a diet with $23.5 \%$ flaxseed oil is recommended to increase the total n-3 PUFA concentration of trout fillets. Also, the trout from this treatment were lowest in saturated fat and highest in ALA. These findings, combined with positive human clinical trial outcomes using the same trout, are highly marketable to producers and consumers.

The significantly decreased DHA and EPA levels were contrary to our expectations. The lower DHA and EPA concentrations might be due to the increased concentration of ALA. It seems that there was minimal elongation and desaturation of ALA to form EPA and DHA by our rainbow trout. Even the trout that received the basal diet, containing fish oil as a source of EPA and DHA, had lower EPA and DHA concentrations after 4 months than at baseline. Bell and others (2003) have shown that after using dietary supplementation with vegetable oil, EPA and DHA can be partially restored in salmon fed diets containing only fish oil before harvest.

Although Greene and Selivonchick (1990) also tested the effects of flaxseed oil on rainbow trout muscle lipids, our experimental methods and diets differed in some aspects. They were able to store diets at a cooler temperature $\left(-34.4^{\circ} \mathrm{C}\right)$. Trout, known to 
be 11 months, were fed a flaxseed oil diet for 140 days and fasted for three days prior to selection and obtaining fillets. Because our 23.5\% flaxseed oil diet had much higher percentages of ALA (46.22\% rather than 25.81\%) and total n-3 fat, we produced trout fillets with higher percentages of ALA (26.66\% compared to $14.27 \%)$ and total n-3 fats (39.37\% compared to $30.29 \%$ ) in only 120 days. Our results for EPA and DHA were rather similar. We observed 2.62\% EPA and 7.94\% DHA, compared to the respective $2.03 \%$ and $9.81 \%$ that was previously found. Our trout very nearly achieved the $8-10 \%$ DHA that Greene and Selivonchick considered optimum for rainbow trout muscle raised under their experimental conditions, while ALA in our study was much more increased.

Studies examining human conversion of ALA to DHA and EPA have resulted in mixed outcomes. In 1994, Emken and others reported a 15\% conversion. Although more recently, the metabolism of ALA to DHA and EPA was shown to be just $0.2 \%$ (Pawlosky 2001). Both studies detail that the elongation to DHA is far less than that to EPA. It can be agreed upon that some dietary ALA is converted to DHA and EPA in our bodies.

Our study had several drawbacks. The experimental trial was conducted outside during the winter for four months. Weather pattern and temperature changes were not recorded, and changes in climate may have had an effect on the results. Sold by a private grower, trout were reported to be one year old. However, actual age of the fish was unknown, and a number of trout were mature with eggs. Ideally, the trout should have been immature. Therefore, future studies should use more uniform fingerlings of known age. It is also possible that outcomes may differ with longer treatment. It remains to be seen if the decreases in DHA and EPA would have a parabolic nature over time or if ALA concentrations would continue to rise. 
The $\mathrm{n}-3$ enhanced trout fillets from the $23.5 \%$ FO group were used in a separate human clinical trial at West Virginia University's Health Sciences Center among 24 healthy postmenopausal women (Siu 2005). They were randomly assigned to a fish group (usual diet plus two servings of n-3 PUFA enriched fish per week) or a control group (usual diet with no fatty fish). The researchers stated that each 4-ounce serving provided 0.88 grams of ALA, 0.08 grams of EPA, and 0.35 grams of DHA. Women in the fish group had a lower BMI (23.6 vs. $\left.28.1 \mathrm{~kg} / \mathrm{m}^{2}, \mathrm{p}<0.01\right)$ and consumed fewer calories from fat ( 33.5 vs. $39.8 \%$ of total intake, $p<0.05$ ) compared to the control. All 13 women in the fish group enjoyed the taste of the fillets. Although preparation methods of the trout fillets varied, Gall and others (1983) showed that the fatty acid profile of fish is not affected by cooking methods other than deep-fat frying. The women reported $100 \%$ compliance. After eight weeks of feeding, the results showed a positive effect on blood lipids. Women in the n-3 PUFA fish group had a significant reduction in total cholesterol $(\mathrm{p}=0.03)$ and a nonsignificant decrease mean triglyceride levels $(\mathrm{p}=0.08)$ compared to those in the control. The mean total cholesterol difference was $9.2 \mathrm{mg} / \mathrm{dL}$ less for the $\mathrm{n}-3$ PUFA fish group, while the levels increased an average of $3.7 \mathrm{mg} / \mathrm{dL}$ among the control group.

Additionally, a storage stability study was later conducted in the flaxseed oil supplemented trout fillets to examine the effects of vitamin E supplementation, oxygen depletion from vacuum packing, and temperature on fat content and lipid oxidation. The results indicate that feed should be supplemented with alpha-tocopheryl acetate ( $\alpha$-TA) to maintain total n-3 PUFA during storage. Fillets from the 23.5\% FO diet with 1500ppm $\alpha$-TA added had the lowest $(\mathrm{P}<0.05)$ proportion of saturated FA as well as the highest 
$(\mathrm{P}>0.05)$ proportions of unsaturated FA, total n-3 PUFA, and ALA compared to those from other treatment groups. 


\section{Conclusion}

Although studies have shown benefits of n-3 PUFA using fish-oil supplements, it is widely accepted that a food-based approach of eating whole fish is more beneficial (He 2005). Among studies using supplements, doses usually exceed amounts normally found from dietary intake. The safety of supplements can also be questionable, as the FDA does not regulate them. On the other hand, fish meat contains protein, amino acids, and other trace elements important to health. Research concerning the relationship between n-3 PUFA and other nutrients found in fish is needed.

Fish consumption in the United States appears to be influenced by a number of factors. The public may be hesitant to consume fish as a source of n-3 PUFA due to the price, perceived mercury content, taste, freshness, and availability. Health professionals must continue educating individuals concerning the safety of eating fish and emphasizing their health benefits. Although currently more prevalent outside of the United States, avian influenza and "mad cow" disease outbreaks within the U.S. would drastically affect supply of poultry and beef, thereby raising cost prices. Fear of these diseases may lead to decreased poultry and beef consumption and a possible shift toward fish.

The marketability of fish can be strengthened with an increased n-3 PUFA content. However, supplementing fish feed with flaxseed oil adds additional costs to the producer. These costs would be carried over to consumers, raising the price one would pay for n-3 PUFA enriched fish compared to standard fish. For retailing companies concerned with profit and bottom lines, what effect would an increase in price have on consumers considering the enriched fish? If trends seen with n-3 PUFA enriched eggs hold true for n-3 PUFA enriched fish, consumers would not be deterred by a higher cost. 
Initial acceptability studies and strong sales positively indicate that n-3 PUFA enriched eggs, which cost more than ordinary eggs, are seen as worth the extra cost. Using survey data from over 500 consumers in Texas, Marshall and others (1994) found 65\% reported a willingness to purchase an n-3 PUFA enriched egg. More surprisingly, 71\% were willing to pay an additional $\$ 0.50$ per dozen, indicating that consumers are willing to put their money where their mouths and health benefits lie.

In conclusion, consuming adequate levels of n-3 PUFA is essential for human health. Researchers recommend eating fish at least once a week and increasing n-3 PUFA intake to protect against cardiac events and death. Supplementing rainbow trout diets with flaxseed oil and vitamin $\mathrm{E}$, in the form of alpha-tocopheryl acetate, not only increased the total omega-3 fat concentration, significantly higher ALA and lower saturated fat levels were achieved. 


\section{References}

Ackman RG. Fish lipids, part 1. Advances in fish sciences and technology. Farnham (UK); Fishing News Books. 1980. 86-103.

Albert CM, Hennekens CH, O'Donnell CJ, Ajani UA, Carey VJ. Fish consumption and risk of sudden cardiac death. JAMA. 1998; 279:23-7.

Ascherio A, Rimm EB, Giovannucci EL, et al. Dietary fat and risk of coronary heart disease in men: cohort follow up study in the United States. BMJ. 1996; 313: 8490 .

Association of Official Analytical Chemists (AOAC). Official Methods of Analysis of the Association of Official Analytical Chemists, $16^{\text {th }}$ ed. Washington, DC: Association of Official Analytical Chemists; 1995.

Baylin A, Campos H. Arachidonic acid in adipose tissue is associated with nonfatal acute myocardial infarction in the central valley of Costa Rica. J Nutr. 2004; 134, 3095-3099.

Bell JG, Henderson RJ, Tocher DR, et al. Altered fatty acid composition in Atlantic salmon (Salmo salar) fed diets containing linseed and rapeseed oils can be partially restored by a subsequent fish oil finishing diet. J Nutr. 2003; 133: 27932801.

Chaiyapechara S, Liu KM, Barrows FT, Hardy FW, Dong FM. Proximate composition, lipid oxidation, and sensory characteristics of fillets from rainbow trout Oncorhynchus mykiss fed diets containing 10\% to 30\% lipid. Journal of the World Aquaculture Society. 2003; 34(3):266-277.

Connor WE. Importance of n-3 fatty acids in health and disease. Am J Clin Nutr. 2000; 71 (1 Suppl): 171S-175S.

Daviglus ML, Stamler J, Orencia AJ, et al. Fish consumption and the 30-year risk of fatal myocardial infarction. N Engl J Med. 1997; 336: 1046-1053.

Djousse L, Pankow JS, Eckfeldt JH, et al. Relation between dietary linolenic acid and coronary artery disease in the National Heart, Lung, and Blood Institute Family Heart Study. Am J Clin Nutr. 2001; 74: 612-619.

Emken EA, Adlof RO, Gulley RM. Dietary linoleic acid influences desaturation and acylation of deuterium-labeled linoleic and linolenic acids in young adult males. Biochim Biophys Acta. 1994; 1213: 277-288. 
Gall KL, Otwell WS, Koburger JA, et al. Effects of four cooking methods on the proximate, mineral and fatty acid composition of fish fillets. J Food Sci. 1983; 48: 1068-1074.

Gottlieb S. Good fats and bad fats. Available at: http://www.diabetes.org/diabetes-cholesterol/faqs-fat.jsp

Greene DHS, Selivonchick DP. Effects of dietary vegetable, animal and marine lipids on muscle lipid and hematology of rainbow trout (Oncorhynchus mykiss). Aquaculture. 1990; 89:165-182.

Hardy R. "Farmed fish and omega-3 fatty acids." Aquaculture Magazine. March/April 2003: 63-65.

Harvard Medical School Health. Nutrition. Harvard Women's Health Watch. June 2002: $9 ; 10$.

He K, Daviglus ML. A few more thoughts about fish and fish oil. J Am Diet Assoc. 2005; 105(3): 350-351.

Henderson RJ, Tocher DR. The lipid composition and biochemistry of freshwater fish. Prog Lipid Res. 1987;26(4):281-347.

Hu FB, Bronner L, Willett WC, Stampfer MJ, Rexrode KM, Albert CM, Hunter D, Manson JE. Fish and omega-3 fatty acid intake and risk of coronary heart disease in women. JAMA. 2002 Apr 10;287(14):1815-21.

Institutes of the Medicine of the National Academies. Dietary Reference Intakes for Energy, Carbohydrate, Fiber, Fat, Fatty Acids, Cholesterol, Protein, and Amino Acids. Washington, DC: National Academy Press; 2002.

Komprda T, Zelenka J, Fajmonova E, Fialova M, Kladroba D. Arachidonic acid and long-chain $\mathrm{n}-3$ polyunsaturated fatty acid contents in meat of selected poultry and fish species in relation to dietary fat sources. J Agric Food Chem. 2005 Aug 24;53(17):6804-12.

Krauss RM, Eckel RH, Howard B, et al. AHA Dietary Guidelines: revision 2000: a statement for healthcare professionals from the Nutrition Committee of the American Heart Association. Circulation. 2000; 102: 2284-2299.

Kris-Etherton PM, Taylor DS, Yu-Poth S, et al. Polyunsaturated fatty acids in the food chain in the United States. Am J Clin Nutr. 2000; 71 (1 Suppl): 179S-188S.

Kris-Etherton P, Harris W, Appel L. Fish consumption, fish oil, omega-3 fatty acids, and cardiovascular disease. Circulation. 2002;106: 2747. 
Marshall AC, Kubena KS, Hinton KR, Hargis PS, Van Elswyk ME. n-3 fatty acid enriched table eggs: a survey of consumer acceptability. Poult Sci. 1994; 73(8): 1334-40.

National Research Council. Composition of feed ingredients. Nutrient Requirements of Fish. Washingtion, DC: National Academy Press. 1993. 64-71.

Nawar WW. Lipids. Food Chemistry, $3^{\text {rd }}$ ed. New York: Marcel Dekker. 1996. 226-314.

Okuyama H, Kobayashi T, Watanabe S. Dietary fatty acids-the n-6/n-3 balance and chronic elderly diseases. Excess linoleic acid and relative n-3 deficiency syndrome seen in Japan. Prog Lipid Res. 1997; 35, 409-457.

Oomen CM, Feskens EJ, Rasanen L, et al. Fish consumption and coronary heart disease mortality in Finland, Italy, and The Netherlands. Am J Epidemiol. 2000; 151: 999-1006.

Pawlosky RJ, Hibbeln JR, Novotny JA, et al. Physiological compartmental analysis of alpha-linolenic acid metabolism in adult humans. J Lipid Res. 2001; 42: $1257-$ 1265.

Sinclair R. Good, bad or essential fats: what is the story with omega-3? Nutrition and Food Science. 2000; 30: 178-184.

Siu E. Fatty fish consumption lowers lipids but not inflammatory markers in women. 2005.

Turner M, Lumb R, West J. Effects of increased dietary marine fish oil on the omega-3 fatty acid content of rainbow trout fillets. The Progressive FishCulturist. 1990; 52: 130-133.

United States Departments of Agriculture and Health and Human Services. Dietary Guidelines for Americans 2005, Chapter 6 Fats. Available at: http://www.health.gov/dietaryguidelines/dga2005/document/html/chapter6.htm

United States Food and Drug Administration, Center for Food Safety and Applied Nutrition. Qualified health claims subject to enforcement discretion, omega-3 fatty acids and coronary heart disease. 9/08/2004; Docket No. 2003Q-0401. Updated August 2005 and November 2005. Available at: http://www.cfsan.fda.gov/ dms/qhc-sum.html

$\mathrm{Yu}$ TC, Sinnhuber RO. Growth response of rainbow trout (Salmo gairgneri) to dietary n3 and n6 fatty acids. Aquculture. 1976; 8: 309-317.

Yu TC, Sinnhuber RO, Putnam G. Effect of dietary lipids on fatty acid composition of rainbow trout. Lipids. 1977; 12: 495-499. 
Yu T, Sinnhuber R, Hendricks J. Reproduction and survival of rainbow trout (Salmo gairdneri) fed linolenic acid as the only source of essential fatty acids. Lipids. 1979; 14: 572-575. 